\title{
OPEN High molecular weight adiponectin levels are inversely associated with adiposity in pediatric brain tumor survivors
}

\begin{abstract}
Rebecca Ronsley ${ }^{1}$, Shahrad Rod Rassekh ${ }^{1}$, Adam Fleming ${ }^{2,3}$, Brianna Empringham ${ }^{2,4}$, William Jennings ${ }^{2,4}$, Carol Portwine ${ }^{2,3}$, Sarah Burrow ${ }^{5}$, Shayna Zelcer ${ }^{6}$, Donna L. Johnston ${ }^{7}$, Lehana Thabane ${ }^{8,9,10,11} \&$ M. Constantine Samaan ${ }^{2,4,8,12 \bowtie}$

While children with brain tumors are surviving at record rates, survivors are at risk of cardiovascular disease and type 2 diabetes mellitus; these conditions may be driven by excess body fat. Adiponectin in an adipokine that is inversely associated with the fat mass, and has been linked to cardiometabolic risk stratification in the general population. However, adiponectin's profile and determinants in SCBT have not been established. We tested the hypothesis that high molecular weight (HMW) adiponectin levels, the more biologically active form of adiponectin, were associated with adiposity in SCBT similarly to non-cancer controls. Seventy-four SCBT ( $n=32$ female) and 126 controls $(n=59$ female) who were 5-17 years old were included. Partial correlations and multivariable regression analyses assessed the relationship between HMW adiponectin and adiposity. HMW adiponectin was inversely associated with total and central adiposity $(\mathrm{FM} \%: \beta-0.21,95 \% \mathrm{Cl}-0.15,-0.08 ; p$ value $<0.0001$; WHR: $\beta-0.14,95 \% \mathrm{Cl}-0.02,-0.01 ; p$ value $<0.0001$; WHtR: $\beta-0.21,95 \% \mathrm{Cl}-0.05$, $-0.03 ; p$ value $<0.0001$ ). In conclusion, $\mathrm{HMW}$ adiponectin is inversely correlated with adiposity in SCBT. Adiponectin may serve as a biomarker of cardiometabolic risk and response to interventions to prevent and manage obesity and its comorbidities in SCBT.
\end{abstract}

One-third of the world's population is overweight or obese, and this figure includes tens of millions of children ${ }^{1-5}$. These rates are significant, as childhood obesity persists into adulthood, and obesity-driven cardiovascular diseases and type 2 diabetes mellitus contribute to $4,000,000$ adult deaths globally ${ }^{6,7}$. Obesity is a driver of the global epidemic of chronic non-communicable diseases, and is a significant public health challenge ${ }^{6}$.

Survivors of childhood brain tumors (SCBT) is an emerging group of childhood cancer survivors; this population exhibits vulnerability to premature cardiovascular disease and type 2 diabetes mellitus and early mortality when compared to non-cancer control groups ${ }^{8-10}$. There are multiple reasons for the susceptibility to cardiometabolic disorders in survivors, and an urgent need for interventions that can lower their risk to improve life expectancy and quality of life.

Obesity in children is characterized by the disproportionate expansion of the adipose tissue when compared to muscle and bone compartments $s^{11-13}$, with multiple biological, psychological, and lifestyle drivers of the adipose phenotyp $\mathrm{e}^{14,15}$. Importantly, while SCBT have excess adiposity when compared to controls, the potenial alteration in adipose tissue function is less well understood and may impact metabolic health ${ }^{16}$.

\footnotetext{
${ }^{1}$ Division of Hematology, Oncology and BMT, Department of Pediatrics, University of British Columbia, Vancouver, BC, Canada. ${ }^{2}$ Department of Pediatrics, McMaster University, Hamilton, ON, Canada. ${ }^{3}$ Division of Pediatric Hematology/Oncology, McMaster Children's Hospital, Hamilton, ON, Canada. ${ }^{4}$ Division of Pediatric Endocrinology, McMaster Children's Hospital, Hamilton, ON, Canada. ${ }^{5}$ Division of Pediatric Orthopedics, Department of Surgery, McMaster University, Hamilton, ON, Canada. ${ }^{6}$ Division of Pediatric Hematology Oncology, Children's Hospital, London Health Sciences Center, London, ON, Canada. ${ }^{7}$ Division of Pediatric Hematology/Oncology, Children's Hospital of Eastern Ontario, Ottawa, ON, Canada. ${ }^{8}$ Department of Health Research Methods, Evidence and Impact, McMaster University, Hamilton, ON, Canada. ${ }^{9}$ Department of Anesthesia, McMaster University, Hamilton, ON, Canada. ${ }^{10}$ Centre for Evaluation of Medicines, St. Joseph's Health Care, Hamilton, ON, Canada. ${ }^{11}$ Biostatistics Unit, St Joseph's Healthcare-Hamilton, Hamilton, ON, Canada. ${ }^{12}$ Michael G. De Groote School of Medicine, McMaster University, Hamilton, ON, Canada. ${ }^{\circledR}$ email: samaanc@mcmaster.ca
} 


\begin{tabular}{|l|l|l|}
\hline \multirow{2}{*}{ Variables } & SCBT & Controls \\
\cline { 2 - 3 } & $($ Mean \pm SD, $\mathbf{n}=\mathbf{7 4})$ & $($ Mean \pm SD, $\mathbf{n}=\mathbf{1 2 6})$ \\
\hline Age $($ years $)$ & $15.10 \pm 7.30$ (range 5.20-42.70) & $14.00 \pm 2.70$ (range 5.40-18.80) \\
\hline Height $(\mathrm{cm})$ & $151.10 \pm 25.20$ & $162.20 \pm 15.10$ \\
\hline WMight $(\mathrm{kg})$ & $53.30 \pm 24.60$ & $60.10 \pm 22.00$ \\
\hline Body fat percentage $(\mathrm{n}=180)$ & $0.45 \pm 1.20$ & $0.52 \pm 1.10$ \\
\hline Waist-to-hip ratio $(\mathrm{n}=198)$ & $25.00 \pm 10.00$ (range 9-51) & $22.70 \pm 9.80$ (range 6-47) \\
\hline Waist-to-height ratio $(\mathrm{n}=198)$ & $0.87 \pm 0.08($ range $0.71-1.06)$ & $0.83 \pm 0.10$ (range 0.65-1.28) \\
\hline Systolic blood pressure $(\mathrm{mmHg})$ & $0.48 \pm 0.07($ range $0.36-0.75)$ & $0.45 \pm 0.08$ (range 0.33-0.79) \\
\hline Diastolic blood pressure $(\mathrm{mmHg})$ & $105.00 \pm 12.00$ & $108.00 \pm 11.00$ \\
\hline Adiponectin $(\mu \mathrm{m} / \mathrm{mL}, \mathrm{n}=49 \mathrm{SCBT}, \mathrm{n}=101$ controls) & $66.00 \pm 9.00$ & $68.00 \pm 9.00$ \\
\hline
\end{tabular}

Table 1. Baseline characteristics of participants. BMI body mass index, $\mathrm{cm}$ centimeter, $\mathrm{kg}$ kilogram, SCBT survivors of childhood brain tumors, SD standard deviation.

One of the most abundant products of the adipose tissue is the adipokine adiponectin. This adipokine has low, medium, and high molecular weight (HMW) isoforms ${ }^{17}$. The latter isoform is composed of $12-18$ monomers and is considered the more relevant active form through which adiponectin exerts its biological actions ${ }^{18}$.

In the general population, obesity is associated with lower circulating adiponectin levels, which are linked to insulin resistance and independently predicts cardiovascular risk ${ }^{19-22}$. Also, weight loss improves circulating adiponectin levels and insulin sensitivity ${ }^{23}$. While studies have described HMW adiponectin profile in children, there are no studies on the association of HMW adiponectin with adiposity in SCBT ${ }^{24-26}$.

We tested the hypothesis that HMW adiponectin was associated with adiposity in SCBT. We also hypothesized that the HMW adiponectin profile was similar in SCBT and non-cancer controls.

\section{Results}

Table 1 reports on baseline demographic, anthropometric, and clinical characteristics of the study participants. The study enrolled 74 SCBT and 126 non-cancer controls.

In SCBT group, the brain tumor types included non-Neurofibromatosis-1 (NF1) $(\mathrm{N}=31,41.90 \%)$ and NF1related low-grade glioma $(\mathrm{N}=11,14.90 \%)$, medulloblastoma $(\mathrm{N}=16,21.60 \%)$, germ cell tumors $(\mathrm{N}=6,8.10 \%)$, subependymal giant cell astrocytoma $(\mathrm{N}=3,4.10 \%)$, ependymoma $(\mathrm{N}=2,2.70 \%)$, craniopharyngioma $(\mathrm{N}=2$, $2.70 \%)$, meningioma $(\mathrm{N}=1,1.40 \%)$, and other $(\mathrm{N}=2,2.70 \%)$. Tumors were distributed almost equally between the supratentorial $(n=35,47.30 \%)$ and infratentorial $(n=39,52.70 \%)$ compartments. The majority of SCBT were treated with surgery $(\mathrm{n}=57,77.00 \%)$, with $30(40.50 \%)$ receiving radiotherapy and $36(48.60 \%)$ receiving chemotherapy.

Both SCBT and non-cancer controls had similar age (SCBT: $15.10 \pm 7.30$ years; controls $14.00 \pm 2.70$ years) and sex distributions (SCBT: $\mathrm{n}=32$ female, $43.20 \%$; controls: $\mathrm{n}=59$ female, $46.80 \%$ ). Of note, the majority of SCBT were pubertal $(\mathrm{n}=109(86.50 \%)$; male $\mathrm{n}=59(88.10 \%)$; female $\mathrm{n}=50(84.70 \%))$, and a similar trend was noted in controls $(n=51(68.90 \%)$; male $n=30(71.40 \%)$; female $n=21(65.60 \%)$.

The mean BMI percentile was $64.20 \%$ for females and $61.40 \%$ for males, while body fat percentage was $26.70 \%$ in females compared to $20.10 \%$ in males.

One-in-four SCBT and one-in-three controls were overweight or obese based on BMI z-score measures (SCBT: overweight $n=13(18.00 \%)$, obesity $n=7$ (9.00\%); controls: overweight $n=22(17 \%)$, obesity $n=23$ $(18.00 \%))$.

The levels of adiponectin were similar in SCBT and controls $(6.40 \pm 5.40$ versus $18.70 \pm 3.90 \mu \mathrm{g} / \mathrm{mL}, p$ value $0.589)$. Females had a higher level of HMW adiponectin when compared to male participants $(6.90 \pm 4.80$ versus $4.80 \pm 3.80 \mu \mathrm{g} / \mathrm{mL}, p$ value 0.041$)$.

To determine the correlations between the fat depots and HMW adiponectin in SCBT and controls, we conducted partial correlation analyses adjusting for age, sex, and puberty (Table 2). Total adiposity (fat mass percentage, FM\%) correlated with central adiposity measures (waist-to-hip ratio (WHR), waist-to-height ratio (WHtR)). Adiponectin was negatively correlated with FM\% and WHtR in survivors but not in controls; there was no correlation between adiponectin and WHR in both populations (Table 2).

To determine the relationship between HMW adiponectin and adiposity, we performed a multivariable linear regression analysis and adjusted for age, sex, puberty, cancer diagnosis, and treatments, including surgery, radiotherapy, and chemotherapy (Table 3 ).

The HMW adiponectin was negatively associated with total and central adiposity measures (FM\%: $\beta-0.21$, 95\% CI $-0.15,-0.08, p$ value $<0.0001$; WHR: $\beta-0.14,95 \% \mathrm{CI}-0.02,-0.01, p$ value $<0.0001$; WHtR: $\beta-0.21$, $95 \% \mathrm{CI}-0.05,-0.03, p$ value $<0.0001)$. Having a brain tumor diagnosis and older age were associated with adiposity, as well as female sex except for WHtR. Treatments and puberty had no significant association with adiposity.

In conclusion, HMW adiponectin was inversely associated with total and central adiposity measures in SCBT and non-cancer controls. 


\begin{tabular}{|c|c|c|c|c|c|c|}
\hline Population & Variables & Correlations ( $p$ value) & FM\% & WHR & WHtR & Adiponectin \\
\hline \multirow{6}{*}{ SCBT } & \multirow{2}{*}{ FM\% } & $\mathrm{r}$ & 1 & 0.4 & 0.77 & -0.42 \\
\hline & & $p$ value & - & 0.006 & $<0.0001$ & 0.015 \\
\hline & \multirow{2}{*}{ WHR } & $\mathrm{r}$ & 0.4 & 1 & 0.61 & -0.2 \\
\hline & & $p$ value & 0.006 & - & $<0.0001$ & 0.27 \\
\hline & \multirow{2}{*}{ WHtR } & $\mathrm{r}$ & 0.77 & 0.61 & 1 & -0.37 \\
\hline & & $p$ value & $<0.0001$ & $<0.0001$ & - & 0.032 \\
\hline \multirow{6}{*}{ Controls } & \multirow{2}{*}{ FM\% } & $\mathrm{r}$ & 1 & 0.3 & 0.77 & -0.14 \\
\hline & & $p$ value & - & 0.001 & $<0.0001$ & 0.161 \\
\hline & \multirow{2}{*}{ WHR } & $\mathrm{r}$ & 0.3 & 1 & 0.68 & -0.12 \\
\hline & & $p$ value & 0.001 & - & $<0.0001$ & 0.27 \\
\hline & \multirow{2}{*}{ WHtR } & $\mathrm{r}$ & 0.77 & 0.68 & 1 & -0.14 \\
\hline & & $p$ value & $<0.0001$ & $<0.0001$ & - & 0.171 \\
\hline
\end{tabular}

Table 2. Partial correlations of the different fat depots and adiponectin adjusted for age, sex, and puberty in SCBT and controls. FM\% fat mass percentage, 95\% CI 95\% confidence interval, SCBT survivors of childhood brain tumors, WHR waist-to-hip ratio, WHtR waist-to-height ratio.

\begin{tabular}{|c|c|c|c|c|}
\hline \multirow[b]{2}{*}{ Variables } & \multirow[b]{2}{*}{$\beta$} & \multicolumn{2}{|l|}{$95 \% \mathrm{CI}$} & \multirow[b]{2}{*}{$p$ value } \\
\hline & & Upper & Lower & \\
\hline \multicolumn{5}{|c|}{ Dependent variable: FM\% } \\
\hline Adiponectin & -0.21 & -0.15 & -0.08 & $<0.0001$ \\
\hline Age & 0.26 & 0.23 & 0.53 & $<0.0001$ \\
\hline Sex & 0.41 & 0.13 & 0.18 & $<0.0001$ \\
\hline Cancer status & 0.16 & 0.04 & 0.1 & $<0.0001$ \\
\hline \multicolumn{5}{|c|}{ Dependent variable: waist-to-hip ratio } \\
\hline Adiponectin & -0.14 & -0.02 & -0.01 & $<0.0001$ \\
\hline Age & 0.12 & 0.01 & 0.07 & 0.016 \\
\hline Sex & -0.13 & -0.02 & -0.01 & $<0.0001$ \\
\hline Cancer status & 0.19 & 0.012 & 0.024 & $<0.0001$ \\
\hline \multicolumn{5}{|c|}{ Dependent variable: waist-to-height ratio } \\
\hline Adiponectin & -0.21 & -0.05 & -0.03 & $<0.0001$ \\
\hline Age & 0.27 & 0.08 & 0.18 & $<0.0001$ \\
\hline Sex & -0.004 & -0.01 & 0.01 & 0.91 \\
\hline Cancer status & 0.11 & 0.01 & 0.03 & 0.001 \\
\hline
\end{tabular}

Table 3. Regression analysis for the association of adiponectin, age, sex, and cancer status in SCBT and controls. 95\% CI 95\% confidence interval, SCBT survivors of childhood brain tumors, WHR waist-to-hip ratio, WHtR waist-to-height ratio.

\section{Discussion}

Over the past few decades, the number of children surviving brain tumors has reached record rates. However,

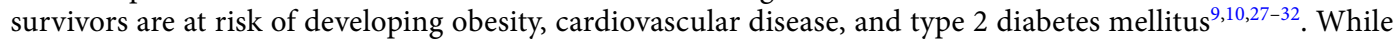
childhood obesity and dysglycemia drive early adult mortality ${ }^{33}$, SCBT have higher rates of adverse cardiometabolic outcomes and premature mortality than the general population but with similar BMI-defined obesity rates $^{9,10,16,27-32,34}$.

Importantly, SCBT have higher adiposity at similar BMI levels when compared to non-cancer controls ${ }^{16,35}$, and while the fat mass is a component of total body mass, it is a superior predictor of cardiometabolic risk in the general population versus $\mathrm{BMI}^{36-43}$.

Therefore, identifying biomarkers of the fat mass may help clarify which SCBT are at risk of cardiometabolic morbidities and mortality to target them with interventions that attempt to improve outcomes. This study has demonstrated that circulating HMW adiponectin is a biomarker of the fat mass in SCBT and that it follows the same trends observed in the non-cancer control group.

Adiponectin is a $30 \mathrm{kDa}$ molecule secreted predominantly by adipocytes.

The endoplasmic reticulum plays an important role in regulating the synthesis and secretion of adiponectin, whereby Endoplasmic Reticulum resident protein 44 (ERp44) inhibits adiponectin secretion by retaining its oligomers ${ }^{44}$. The Endoplasmic Reticulum Oxidoreductase 1 alpha (Ero1-La) releases the ERp44-bound oligomers ${ }^{45}$. Adiponectin has significant Immunometabolic effects, including actions in insulin sensitivity and 
inflammation ${ }^{19,46}$. The mechanisms of adiponectin downregulation in obesity are not fully understood, but it may be related to adipose tissue macrophage secretion of Tumor Necrosis Factor Alpha (TNFa) and oxidative stress suppressing adiponectin gene expression ${ }^{47-51}$.

The HMW adiponectin levels trended higher in females when compared to male participants. Our results are consistent with current data in the general pediatric population ${ }^{26,46,52-55}$, with obese boys having the lowest levels when compared to girls and lean children, as the androgen rise with puberty in boys is associated with reduced adiponectin level ${ }^{55,56}$. In our cohort, the majority of participants were pubertal, and the number of prepubertal subjects was quite small and we could not verify the impact of puberty on adiponectin levels in survivors.

Children with central adiposity have lower adiponectin levels compared to those with normal central fat ${ }^{52}$. Also, patients with type 2 diabetes mellitus have lower adiponectin levels when compared to people with no diabetes $^{57}$. This negative association of adiposity with adiponectin is consistent with the inflammatory response within visceral fat and immune cell infiltration and inflammatory cytokine secretion within this depot which may suppress adiponectin production ${ }^{58}$.

While SCBT have not had their adiponectin levels measured previously, pediatric leukemia and lymphoma patients have had their adiponectin profile interrogated. These studies demonstrated that adiponectin correlated with BMI-z score, sex, and puberty ${ }^{59-62}$. Our data highlight that the adipose tissue of brain tumor survivors likely has similar biological profile to that of survivors of other pediatric cancers and the general pediatric population, and further study of the adipose tissue is needed to understand the impact of the tumor and its treatment on adipose tissue Immunometabolism.

The role of adiponectin as an anti-inflammatory, and at times as an inflammatory, molecule has been debated $^{17,63}$. Further analysis of adiponectin actions in SCBT is needed as a biomarker of adipose mass and to assess responses to interventions targeting adiposity and cardiometabolic risk.

One strength of this analysis involved the use of measures of total and central adiposity in assessing the relationship between adiponectin and the adipose profile in SCBT. Furthermore, we were able to compare SCBT to a healthy non-cancer control group in our analysis, providing a unique comparison population for this study.

One limitation of this study is that due to its cross-sectional design, it was not possible to elicit longitudinal changes in HMW adiponectin levels from diagnosis and into follow-up, and link that profile with future health outcomes. Furthermore, as the sample size is relatively small, tumor subgroup analyses were not possible to maintain the power of the study.

Future studies need to assess survivors with different tumors at sufficient numbers longitudinally to determine the potential association of adiponectin with other metabolic parameters in this population including glucose homeostasis. Whether adiponectin during childhood can predict future cardiometabolic outcomes in SCBT requires further assessment.

\section{Conclusions}

In this study, adiposity in SCBT was inversely associated with HMW adiponectin levels. This population is highly vulnerable to adverse cardiometabolic disorders.

The insulin-sensitizing, anti-inflammatory, and anti-atherogenic effects of adiponectin makes it a critically vital molecule to study in survivors, as it may serve as a biomarker of future cardiovascular and type 2 diabetes risk. Adiponectin may also act as a marker of response to interventions aiming to prevent, delay, and treat obesity and its cardiometabolic comorbidities in pediatric brain tumor survivors.

\section{Methods}

Study design. This study was a cross-sectional investigation conducting a secondary analysis of data from the Canadian Study of Determinants of Endometabolic Health in ChIlDrEn (CanDECIDE study) cohort. The full protocol for this study and its feasibility has been previously published ${ }^{64,65}$. This study was approved by the Hamilton Integrated Research Ethics Board, and the methods adhered to the relevant regulations and guidelines.

Participants. Participants were recruited from the endocrine, oncology, and orthopedics clinics at McMaster Children's Hospital, a Tertiary Pediatric Academic Center in Hamilton, Ontario, Canada. Participants included children between 5-17 years of age, who are either lean, overweight, or obese based on their body mass index z-score (BMI z-score) as defined by standard criteria ${ }^{66}$. SCBT had to have completed therapy for at least six months before study enrolment.

Participants were excluded due to active infections or a history of infections within 14 days before participation, history of autoimmune disorders, or using immunosuppressive therapy or systemic steroids at a dose higher than maintenance dosing $\left(6-8 \mathrm{mg} / \mathrm{m}^{2} /\right.$ day), or had a history of smoking. We excluded participants and families who were unable to provide consent ${ }^{64,65}$.

Participants 16 years and older provided written informed consent. For participants between 7 and 15 years of age, the parent or guardian supplied written informed consent, and the participant provided assents. For those below seven years of age, the parent or guardian provided written informed consent before study inclusion. The study participation rate was $26.8 \%$ as previously reported ${ }^{65}$.

Data collection. We collected clinical measures, including height, weight, waist circumference, hip circumference, blood pressure, and adiposity data. Questionnaires were also administered to participants' parents and to participants at study visits to collect sociodemographic data, past medical history, and pubertal stage (using validated Tanner pubertal staging pictures). Clinical data, including diagnosis and treatment details, were also collected and verified from medical notes. 
Clinical measures and variable definitions. We collected anthropometric measures including height that was assessed with a stadiometer and measured to the closest $0.1 \mathrm{~cm}$. We measured weight to the nearest $0.1 \mathrm{~kg}$ using an electronic scale (Seca, USA). We calculated the BMI using a standard formula of weight (kg)/ [height $(\mathrm{m})]^{2}$ and the BMI percentile using the Children's BMI Tool for Schools ${ }^{66}$. We measured the BMI z-score using the Centers for Disease Control and Prevention growth chart ${ }^{67}$. We measured Total adiposity by bioelectrical impedance analysis using the Tanita body fat monitor (Tanita Corporation, Illinois, USA). We measured waist circumference and hip circumference using a spring-loaded tape measure. We then calculated the waistto-hip and waist-to-height ratios to assess central adiposity ${ }^{64,65}$.

Enzyme-Linked Immunosorbent Assay (ELISA) for adiponectin. We collected blood samples into EDTA tubes in the fasted state. Centrifugation of the samples took place at room temperature for $15 \mathrm{~min}$ at $1,500 \mathrm{~g}$ to isolate plasma. We stored the samples in cryovials at $-80^{\circ} \mathrm{C}$. When preparing the samples for the assay, the samples were centrifuged at room temperature for $15 \mathrm{~min}$ at $1500 \mathrm{~g}$ after they were thawed on ice. The high molecular weight Adiponectin levels were quantified using the commercially available enzyme-linked immunosorbent assay (ELISA) Human HMW Adiponectin/Acrp30 Quantikine ELISA Kit (R\&D Systems, Minneapolis, USA) as per manufacturer's guidelines ${ }^{68}$.

Statistical analysis. We used the method of Norman and Streiner to calculate sample size ${ }^{69}$. We report the demographic data and baseline variables using descriptive analyses based on the variable type. We report continuous variables as mean $\pm \mathrm{SD}$ and categorical variables as numbers (\%). We tested the data for normality of distribution using the Shapiro-Wilk test, and non-normally distributed data were log-transformed. We tested for colinearity using variance inflation factor.

We imputed missing data in SPSS and included five imputations per missing variable. After variable selection, the output dataset encompassed our original data set with the imputed missing data and a set of cases with imputed values generated by the program ${ }^{70}$. The variables that were imputed included fat mass percentage $(n=20 / 200)$, waist-to-hip ratio $(2 / 200)$, waist-to-height ratio $(2 / 200)$, and adiponectin $(n=50 / 200)$. The validity of our methods has already been established with the percentage of imputations that will maintain data validity $^{70-73}$.

We used partial correlations to assess adiponectin's association with fat mass percentage, WHR, and WHtR and adjusted for age, sex, and puberty. An independent sample t-test was used to assess the differnces in adipose depots and total and sex-specific differences in HMW adiponectin levels.

We conducted a multivariable regression analysis to assess the relationship between adiposity and HMW adiponectin. Adiposity measures used included total adiposity (FM\%) and central adiposity using WHR and WHtR measures. These analyses had age, sex, puberty, cancer diagnosis, and treatments included as independent variables. Two subjects per variable were needed to address the association of adiponectin with adiposity ${ }^{74}$. Therefore, the number of participants in the SCBT and the control groups has provided valid results.

As fat mass percentage and BMI z-score were co-linear variables, we included only the FM\% in the analysis. We report the results as standardized $\beta$ coefficients with $95 \% \mathrm{CI}$ and associated $p$ values. SPSS version 25.0 was used to conduct all analyses ${ }^{75}$.

\section{Data availability}

The study data are available from the corresponding author upon reasonable justification.

Received: 31 March 2020; Accepted: 19 October 2020

Published online: 29 October 2020

\section{References}

1. Reilly, J. J. Obesity in childhood and adolescence: evidence based clinical and public health perspectives. Postgrad. Med. J. 82, 429-437 (2006).

2. WHO. Fact Sheet: Childhood Overweight and Obesity. https://www.who.int/dietphysicalactivity/childhood/en (2013).

3. De Onis, M., Blössner, M. \& Borghi, E. Global prevalence and trends of overweight and obesity among preschool children. Am. J. Clin. Nutr. 92, 1257-1264 (2010).

4. Wang, Y. \& Lobstein, T. Worldwide trends in childhood overweight and obesity. Int. J. Pediatr. Obes. 1, 11-25 (2006).

5. Collaboration, N. R. F. Worldwide trends in children's and adolescents' body mass index, underweight, overweight and obesity, in comparison with adults, from 1975 to 2016: a pooled analysis of 2,416 population-based measurement studies with 128.9 million participants. Lancet 390, 2627-2642 (2017).

6. Collaborators, G. O. Health effects of overweight and obesity in 195 countries over 25 years. N. Engl. J. Med. 377, 13-27 (2017).

7. Simmonds, M., Llewellyn, A., Owen, C. \& Woolacott, N. Predicting adult obesity from childhood obesity: a systematic review and meta-analysis. Obes. Rev. 17, 95-107 (2016).

8. Oeffinger, K. C. et al. Chronic health conditions in adult survivors of childhood cancer. N. Engl. J. Med. 355, 1572-1582 (2006).

9. Holmqvist, A. S. et al. Adult life after childhood cancer in Scandinavia: diabetes mellitus following treatment for cancer in childhood. Eur. J. Cancer 50, 1169-1175. https://doi.org/10.1016/j.ejca.2014.01.014 (2014).

10. Yeh, J. M., Nekhlyudov, L., Goldie, S. J., Mertens, A. C. \& Diller, L. A model-based estimate of cumulative excess mortality in survivors of childhood cancer. Ann. Intern. Med. 152(409-417), W131-408. https://doi.org/10.7326/0003-4819-152-7-20100406000005 (2010).

11. Leonard, M. B., Shults, J., Wilson, B. A., Tershakovec, A. M. \& Zemel, B. S. Obesity during childhood and adolescence augments bone mass and bone dimensions. Am. J. Clin. Nutr. 80, 514-523. https://doi.org/10.1093/ajcn/80.2.514 (2004).

12. Huang, T. T., Johnson, M. S., Figueroa-Colon, R., Dwyer, J. H. \& Goran, M. I. Growth of visceral fat, subcutaneous abdominal fat, and total body fat in children. Obes. Res. 9, 283-289. https://doi.org/10.1038/oby.2001.35 (2001).

13. Kim, J. H. \& Park, Y. S. Low muscle mass is associated with metabolic syndrome in Korean adolescents: the Korea National Health and Nutrition Examination Survey 2009-2011. Nutr. Res. 36, 1423-1428. https://doi.org/10.1016/j.nutres.2016.09.013 (2016) 
14. Sallis, J. F. \& Glanz, K. The role of built environments in physical activity, eating, and obesity in childhood. Future Child. 16, 89-108. https://doi.org/10.1353/foc.2006.0009 (2006).

15. Qasim, A. et al. On the origin of obesity: identifying the biological, environmental and cultural drivers of genetic risk among human populations. Obes. Rev. 19, 121-149 (2018).

16. Wang, K. W. et al. Adiposity in childhood brain tumors: a report from the Canadian Study of Determinants of Endometabolic Health in Children (CanDECIDE Study). Sci. Rep. 7, 45078. https://doi.org/10.1038/srep45078 (2017).

17. Luo, Y. \& Liu, M. Adiponectin: a versatile player of innate immunity. J. Mol. Cell Biol. 8, 120-128. https://doi.org/10.1093/jmcb/ mjw012 (2016).

18. van Andel, M., Heijboer, A. C. \& Drent, M. L. Adiponectin and its isoforms in pathophysiology. Adv. Clin. Chem. 85, 115-147. https://doi.org/10.1016/bs.acc.2018.02.007 (2018).

19. Klünder-Klünder, M., Flores-Huerta, S., García-Macedo, R., Peralta-Romero, J. \& Cruz, M. Adiponectin in eutrophic and obese children as a biomarker to predict metabolic syndrome and each of its components. BMC Public Health 13, 88 (2013).

20. Calcaterra, V. et al. Adiponectin, IL-10 and metabolic syndrome in obese children and adolescents. Acta Biomed. 80, 117-123 (2009).

21. Winer, J. C. et al. Adiponectin in childhood and adolescent obesity and its association with inflammatory markers and components of the metabolic syndrome. J. Clin. Endocrinol. Metab. 91, 4415-4423. https://doi.org/10.1210/jc.2006-0733 (2006).

22. Schulze, M. B. et al. Adiponectin and future coronary heart disease events among men with type 2 diabetes. Diabetes 54, 534-539 (2005).

23. Cambuli, V. M. et al. Assessment of adiponectin and leptin as biomarkers of positive metabolic outcomes after lifestyle intervention in overweight and obese children. J. Clin. Endocrinol. Metab. 93, 3051-3057 (2008).

24. Mi, J. et al. Adiponectin and leptin metabolic biomarkers in chinese children and adolescents. J. Obes. 2010, 892081. https://doi. org/10.1155/2010/892081 (2010).

25. Martos-Moreno, G. A., Barrios, V. \& Argente, J. Normative data for adiponectin, resistin, interleukin 6, and leptin/receptor ratio in a healthy Spanish pediatric population: relationship with sex steroids. Eur. J. Endocrinol. 155, 429-434. https://doi.org/10.1530/ eje.1.02227 (2006).

26. Reinehr, T., Roth, C., Menke, T. \& Andler, W. Adiponectin before and after weight loss in obese children. J. Clin. Endocrinol. Metab. 89, 3790-3794. https://doi.org/10.1210/jc.2003-031925 (2004).

27. Winther, J. F. et al. Risk of cardiovascular disease among Nordic childhood cancer survivors with diabetes mellitus: a report from adult life after childhood cancer in Scandinavia. Cancer 124, 4393-4400. https://doi.org/10.1002/cncr.31696 (2018).

28. Armstrong, G. T. et al. Impact of traditional cardiovascular disease risk factors on long-term cardiovascular outcome in adult survivors of childhood cancer: a report from the Childhood Cancer Survivor Study. J. Clin. Oncol. 29, 9507 (2011).

29. Gurney, J. G. et al. Endocrine and cardiovascular late effects among adult survivors of childhood brain tumors. Cancer 97, 663-673. https://doi.org/10.1002/cncr.11095 (2003).

30. Meacham, L. R. et al. Diabetes mellitus in long-term survivors of childhood cancer - Increased risk associated with radiation therapy: a report for the childhood cancer survivor study. Arch. Intern. Med. 169, 1381-1388. https://doi.org/10.1001/archintern med.2009.209 (2009).

31. Meacham, L. R. et al. Cardiovascular risk factors in adult survivors of pediatric cancer-a report from the childhood cancer survivor study. Cancer Epidemiol. Biomark. Prev. 19, 170-181. https://doi.org/10.1158/1055-9965.EPI-09-0555 (2010).

32. Kero, A. et al. Cardiovascular morbidity in long-term survivors of early-onset cancer: a population-based study. Int. J. Cancer 134, 664-673 (2014).

33. Franks, P. W. et al. Childhood obesity, other cardiovascular risk factors, and premature death. N. Engl. J. Med. 362, 485-493 (2010).

34. Samaan, M. C. \& Akhtar-Danesh, N. The impact of age and race on longevity in pediatric astrocytic tumors: a population-based study. Pediatr. Blood Cancer. https://doi.org/10.1002/pbc.25522 (2015).

35. Wang, K. W. et al. Overweight, obesity and adiposity in survivors of childhood brain tumours: a systematic review and metaanalysis. Clin.Obes. 8, 55-67. https://doi.org/10.1111/cob.12224 (2018).

36. Sherar, L. B. et al. Relationship between trajectories of trunk fat mass development in adolescence and cardiometabolic risk in young adulthood. Obesity 19, 1699-1706 (2011).

37. Oluwagbemigun, K. et al. Developmental trajectories of body mass index from childhood into late adolescence and subsequent late adolescence-young adulthood cardiometabolic risk markers. Cardiovasc. Diabetol. 18, 9 (2019).

38. Allen, N. B. et al. Cardiovascular health trajectories from childhood through middle age and their association with subclinical atherosclerosis. JAMA Cardiol. https://doi.org/10.1001/jamacardio.2020.0140 (2020).

39. Vanderwall, C., Randall Clark, R., Eickhoff, J. \& Carrel, A. L. BMI is a poor predictor of adiposity in young overweight and obese children. BMC Pediatr. 17, 135. https://doi.org/10.1186/s12887-017-0891-z (2017).

40. Savva, S. C., Lamnisos, D. \& Kafatos, A. G. Predicting cardiometabolic risk: waist-to-height ratio or BMI. A meta-analysis. Diabetes Metab. Syndr. Obes. Targets Ther. 6, 403 (2013).

41. Savva, S. et al. Waist circumference and waist-to-height ratio are better predictors of cardiovascular disease risk factors in children than body mass index. Int. J. Obes. 24, 1453-1458 (2000).

42. Panagiotopoulos, C., Ronsley, R., Kuzeljevic, B. \& Davidson, J. Waist circumference is a sensitive screening tool for assessment of metabolic syndrome risk in children treated with second-generation antipsychotics. Can. J. Psychiatry 57, 34-44 (2012).

43. Maynard, L. M. et al. Childhood body composition in relation to body mass index. Pediatrics 107, 344-350 (2001).

44. Scherer, P. E., Williams, S., Fogliano, M., Baldini, G. \& Lodish, H. F. A novel serum protein similar to C1q, produced exclusively in adipocytes. J. Biol. Chem. 270, 26746-26749. https://doi.org/10.1074/jbc.270.45.26746 (1995).

45. Wang, Z. V. et al. Secretion of the adipocyte-specific secretory protein adiponectin critically depends on thiol-mediated protein retention. Mol. Cell Biol. 27, 3716-3731. https://doi.org/10.1128/MCB.00931-06 (2007).

46. Orlando, A., Nava, E., Giussani, M. \& Genovesi, S. Adiponectin and cardiovascular risk. From pathophysiology to clinic: focus on children and adolescents. Int. J. Mol. Sci. 20, 3228 (2019).

47. Ruan, H., Hacohen, N., Golub, T. R., Van Parijs, L. \& Lodish, H. F. Tumor necrosis factor-alpha suppresses adipocyte-specific genes and activates expression of preadipocyte genes in 3T3-L1 adipocytes: nuclear factor-kappaB activation by TNF-alpha is obligatory. Diabetes 51, 1319-1336. https://doi.org/10.2337/diabetes.51.5.1319 (2002).

48. Fasshauer, M., Klein, J., Neumann, S., Eszlinger, M. \& Paschke, R. Hormonal regulation of adiponectin gene expression in 3T3-L1 adipocytes. Biochem. Biophys. Res. Commun. 290, 1084-1089. https://doi.org/10.1006/bbrc.2001.6307 (2002).

49. Degawa-Yamauchi, M. et al. Regulation of adiponectin expression in human adipocytes: effects of adiposity, glucocorticoids, and tumor necrosis factor alpha. Obes. Res. 13, 662-669. https://doi.org/10.1038/oby.2005.74 (2005).

50. Kappes, A. \& Loffler, G. Influences of ionomycin, dibutyryl-cycloAMP and tumour necrosis factor-alpha on intracellular amount and secretion of apM1 in differentiating primary human preadipocytes. Horm. Metab. Res. 32, 548-554. https://doi. org/10.1055/s-2007-978684 (2000).

51. Lumeng, C. N., Deyoung, S. M., Bodzin, J. L. \& Saltiel, A. R. Increased inflammatory properties of adipose tissue macrophages recruited during diet-induced obesity. Diabetes 56, 16-23. https://doi.org/10.2337/db06-1076 (2007).

52. Ochiai, H. et al. Abdominal obesity and serum adiponectin complexes among population-based elementary school children in Japan: a cross-sectional study. BMC Pediatrics 14, 81. https://doi.org/10.1186/1471-2431-14-81 (2014). 
53. Balsan, G. A., Vieira, JLd. C., Oliveira, AMd. \& Portal, V. L. Relationship between adiponectin, obesity and insulin resistance. Revista da Associação Médica Brasileira 61, 72-80 (2015).

54. Woo, J. G., Dolan, L. M., Daniels, S. R., Goodman, E. \& Martin, L. J. Adolescent sex differences in adiponectin are conditional on pubertal development and adiposity. Obes. Res. 13, 2095-2101. https://doi.org/10.1038/oby.2005.260 (2005).

55. Ohman-Hanson, R. A. et al. Ethnic and sex differences in adiponectin: from childhood to adulthood. J. Clin. Endocrinol. Metab. 101, 4808-4815. https://doi.org/10.1210/jc.2016-1137 (2016).

56. Bottner, A. et al. Gender differences of adiponectin levels develop during the progression of puberty and are related to serum androgen levels. J. Clin. Endocrinol. Metab. 89, 4053-4061. https://doi.org/10.1210/jc.2004-0303 (2004).

57. Fisher, F. M. et al. Differences in adiponectin protein expression: effect of fat depots and type 2 diabetic status. Horm. Metab. Res. 34, 650-654. https://doi.org/10.1055/s-2002-38246 (2002).

58. Kralova Lesna, I. et al. Characterisation and comparison of adipose tissue macrophages from human subcutaneous, visceral and perivascular adipose tissue. J. Transl. Med. 14, 208. https://doi.org/10.1186/s12967-016-0962-1 (2016).

59. Kojima, C. et al. Adipocytokines in childhood cancer survivors and correlation with metabolic syndrome components. Pediatr. Int. 55, 438-442 (2013).

60. Barbosa-Cortés, L. et al. Adipokines, insulin resistance, and adiposity as a predictors of metabolic syndrome in child survivors of lymphoma and acute lymphoblastic leukemia of a developing country. BMC Cancer 17, 125 (2017).

61. Srivastava, R. et al. Adiponectin correlates with obesity: A study of 159 childhood acute leukemia survivors from India. Indian J. Cancer 52, 195 (2015).

62. Moschovi, M. et al. Serial plasma concentrations of adiponectin, leptin, and resistin during therapy in children with acute lymphoblastic leukemia. J. Pediatr. Hematol. Oncol. 32, e8-e13 (2010).

63. Yokota, T. et al. Adiponectin, a new member of the family of soluble defense collagens, negatively regulates the growth of myelomonocytic progenitors and the functions of macrophages. Blood 96, 1723-1732 (2000).

64. Samaan, M. C. et al. Recruitment feasibility to a cohort study of endocrine and metabolic health among survivors of childhood brain tumours: a report from the Canadian study of Determinants of Endometabolic Health in ChIlDrEn (CanDECIDE). BMJ Open 4, e005295. https://doi.org/10.1136/bmjopen-2014-005295 (2014).

65. Samaan, M. C., Thabane, L., Burrow, S., Dillenburg, R. F. \& Scheinemann, K. Canadian Study of Determinants of Endometabolic Health in ChIlDrEn (CanDECIDE study): a cohort study protocol examining the mechanisms of obesity in survivors of childhood brain tumours. BMJ Open https://doi.org/10.1136/bmjopen-2013-002869 (2013).

66. Nihiser, A. J. et al. Body mass index measurement in schools. J. Sch. Health 77, 651-671 (2007).

67. Kuczmarski, R. J. 2000 CDC Growth Charts for the United States: methods and development. (Department of Health and Human Services, Centers for Disease Control and Prevention, National Center for Health Statistics, 2002).

68. Sims, E. D. et al. Circulating leptin levels are associated with adiposity in survivors of childhood brain tumors. Sci. Rep. 10, 4711. https://doi.org/10.1038/s41598-020-61520-2 (2020).

69. Norman, G. R. \& Streiner, D. L. PDQ Statistics (B.C. Decker, Hamilton, Ont, 2003).

70. Graham, J. W., Olchowski, A. E. \& Gilreath, T. D. How many imputations are really needed? Some practical clarifications of multiple imputation theory. Prev. Sci. 8, 206-213. https://doi.org/10.1007/s11121-007-0070-9 (2007).

71. Madley-Dowd, P., Hughes, R., Tilling, K. \& Heron, J. The proportion of missing data should not be used to guide decisions on multiple imputation. J. Clin. Epidemiol. 110, 63-73. https://doi.org/10.1016/j.jclinepi.2019.02.016 (2019).

72. Sterne, J. A. et al. Multiple imputation for missing data in epidemiological and clinical research: potential and pitfalls. BMJ 338, b2393. https://doi.org/10.1136/bmj.b2393 (2009).

73. Pedersen, A. B. et al. Missing data and multiple imputation in clinical epidemiological research. Clin. Epidemiol. 9, 157-166. https ://doi.org/10.2147/CLEP.S129785 (2017).

74. Austin, P. C. \& Steyerberg, E. W. The number of subjects per variable required in linear regression analyses. J. Clin. Epidemiol. 68, 627-636. https://doi.org/10.1016/j.jclinepi.2014.12.014 (2015).

75. IBM SPSS Statistics for Windows v. 25.0 (IBM Corp., Armonk, NY, 2017).

\section{Acknowledgements}

We thank the participants and their families for joining this study. We would like to acknowledge Ms. Maggie Hou for her assistance with editorial support.

\section{Author contributions}

M.C.S. is the guarantor. The study question was defined by R.R., S.R.R., A.F., B.E., S.B., C.P., S.Z., D.L.J., W.J., L.T., and M.C.S. R.R., S.R.R., A.F., B.E., S.B., C.P., S.Z., D.L.J., W.J., L.T., and M.C.S. participated in the study design, defining eligibility criteria, and analysis and interpretation of data. The ELISA was performed by W.J. Support in research methods and statistical analysis was provided by L.T. and M.C.S. R.R., S.R.R., and M.C.S. wrote the first draft of the manuscript, and the manuscript was reviewed by all authors, who agreed with its contents.

\section{Funding}

B.E. was funded by Regional Medical Associates (Hamilton) grant.

\section{Competing interests}

The authors declare no competing interests.

\section{Additional information}

Correspondence and requests for materials should be addressed to M.C.S.

Reprints and permissions information is available at www.nature.com/reprints.

Publisher's note Springer Nature remains neutral with regard to jurisdictional claims in published maps and institutional affiliations. 
(c) (i) Open Access This article is licensed under a Creative Commons Attribution 4.0 International cc) License, which permits use, sharing, adaptation, distribution and reproduction in any medium or format, as long as you give appropriate credit to the original author(s) and the source, provide a link to the Creative Commons licence, and indicate if changes were made. The images or other third party material in this article are included in the article's Creative Commons licence, unless indicated otherwise in a credit line to the material. If material is not included in the article's Creative Commons licence and your intended use is not permitted by statutory regulation or exceeds the permitted use, you will need to obtain permission directly from the copyright holder. To view a copy of this licence, visit http://creativecommons.org/licenses/by/4.0/.

(C) The Author(s) 2020 